\title{
Stroke Etiology and Outcomes after Endovascular Thrombectomy: Results from the SITS Registry and a Meta-Analysis
}

\author{
Marius Matusevicius, ${ }^{\mathrm{a}, \mathrm{b}}$ Charith Cooray, ${ }^{\mathrm{a}, \mathrm{c}}$ Viiu-Marika Rand, ${ }^{\mathrm{d}}$ Ana Paiva Nunes, ${ }^{\mathrm{e}}$ Tiago Moreira, ${ }^{\mathrm{a}, \mathrm{c}}$ \\ Rossana Tassi, ${ }^{\mathrm{f}}$ Jose Antonio Egido, ${ }^{\mathrm{g}}$ Jyrki Ollikainen, ${ }^{\mathrm{h}}$ Guido Bigliardi, ${ }^{\mathrm{i}}$ Staffan Holmin, ${ }^{\mathrm{a}, \mathrm{j}}$ Niaz Ahmed ${ }^{\mathrm{a}, \mathrm{c}}$ \\ ${ }^{a}$ Department of Clinical Neuroscience, Karolinska Institute, Stockholm, Sweden \\ bepartment of Research and Education, Karolinska University Hospital, Stockholm, Sweden \\ 'Department of Neurology, Karolinska University Hospital, Stockholm, Sweden \\ ${ }^{d}$ Department of Neurology, North Estonia Medical Centre Foundation, Tallinn, Estonia \\ 'Stroke Unit, Saint Joseph's Hospital, Central Lisbon University Hospital Centre, Lisbon, Portugal \\ fStroke Unit, University Hospital of Siena, Siena, Italy \\ פStroke Unit, Department of Neurology, San Carlos Clinical Hospital, Madrid, Spain

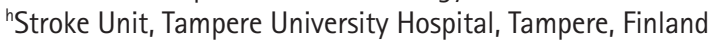 \\ 'Department of Neuroscience, Neurologal Clinic, Civil Hospital of Baggiovara, University Hospital of Modena, Modena, Italy \\ 'Department of Neuroradiology, Karolinska University Hospital, Stockholm, Sweden
}

Background and Purpose The influence of stroke etiology on outcomes after endovascular thrombectomy (EVT) is not well understood. We aimed to investigate whether stroke etiology subgrouped as large artery atherosclerosis (LAA) and cardiac embolism (CE) influences outcomes in large artery occlusion (LAO) treated by EVT.

Methods We included EVT treated LAO stroke patients registered in the Safe Implementation of Treatment in Stroke (SITS) thrombectomy register between January 1, 2014 and September 3, 2019. Primary outcome was successful reperfusion (modified Treatment in Cerebral Infarction 2b3). Secondary outcomes were symptomatic intracranial hemorrhage (SICH), 3-month functional independence (modified Ranking Scale 0-2) and death. Multivariable logistic regression models were used for comparisons. In addition, a meta-analysis of aggregate data from the current literature was conducted (PROSPERO, ID 167447).

Results Of 7,543 patients, 1,903 (25.2\%) had LAA, 3,214 (42.6\%) CE, and 2,426 (32.2\%) unknown, other, or multiple etiologies. LAA patients were younger (66 vs. 74, $P<0.001$ ) and had lower National Institutes of Health Stroke Scale score at baseline (15 vs. $16, P<0.001)$ than CE patients. Multivariable analyses showed that LAA patients had lower odds of successful reperfusion (odds ratio $[\mathrm{OR}], 0.70 ; 95 \%$ confidence interval $[\mathrm{Cl}], 0.57$ to 0.86 ) and functional independence (OR, $0.74 ; 95 \% \mathrm{Cl}, 0.63$ to 0.85$)$, higher risk of death $(\mathrm{OR}, 1.44 ; 95 \% \mathrm{Cl}, 1.21$ to 1.71$)$, but no difference in $\mathrm{SICH}(\mathrm{OR}, 1.09 ; 95 \% \mathrm{Cl}, 0.71$ to 1.66$)$ compared to $\mathrm{CE}$ patients. The systematic review found 25 studies matching the criteria. The meta-analysis did not find any difference between etiologies.

Conclusions From the SITS thrombectomy register, we observed a lower chance of reperfusion and worse outcomes after thrombectomy in patients with LAA compared to CE etiology, despite more favorable baseline characteristics. In contrast, the meta-analysis did not find any difference be-
Correspondence: Marius Matusevicius Department of Clinical Neuroscience, Karolinska Institute, Tomtebodavagen 18A, 17176 Stockholm, Sweden Tel: +46-73-780-2717 Fax: +46-85-248-3049 E-mail: marius.matusevicius@ki.se https://orcid.org/0000-0002-2868-127X

Received: March 8, 2021

Revised: June 21, 2021

Accepted: August 4, 2021 
tween etiologies with aggregate data.

Keywords Ischemic stroke; Embolic stroke; Thrombotic stroke; Thrombectomy; Meta-analysis; Review

\section{Introduction}

The Trial of Org 10172 in Acute Stroke Treatment (TOAST) criteria are widely used to categorize ischemic stroke etiology. ${ }^{1}$ The two most common etiologies of large artery occlusion (LAO) stroke are cardiac embolism (CE) and large artery atherosclerosis (LAA). ${ }^{2}$ The underlying pathogenesis of CE and LAA occlusions are known to be different. ${ }^{3.4}$ Endovascular thrombectomy (EVT) has been shown to be an effective treatment in ischemic stroke, ${ }^{5-11}$ and successful reperfusion after EVT treatment is associated with a good long-term outcome. ${ }^{12,13}$ Stroke etiology is an important factor for stroke prevention, yet it is still unknown whether stroke etiology influences the rates of reperfusion and outcomes after EVT treatment. ${ }^{14-16}$ We aimed to investigate whether different ischemic stroke etiologies influence reperfusion and important outcomes after EVT treatment.

\section{Methods}

\section{Population SITS thrombectomy registry}

We collected data from the Safe Implementation of Treatment in Stroke (SITS) Thrombectomy register. Patients with acute ischemic stroke who underwent EVT treatment due to LAO stroke during January 1st, 2014 to September 3rd, 2019, with or without prior intravenous thrombolysis (IVT), were eligible for this study. Data collection and registration procedures have previously been presented. ${ }^{17,18}$ Centers in the SITS Thrombectomy register commit to report all consecutive cases treated with EVT. This includes baseline and demographic characteristics, stroke severity per National Institutes of Health Stroke Scale (NIHSS), medical history, imaging data, and follow-up evaluation. Imaging studies, neurological status, and follow-up evaluation is performed according to local routines at each individual study center. Symptomatic intracranial hemorrhage (SICH) events were established based on locally read imaging data and clinical data entered into the registry. Study centers with less than 10 registered patients or more than 30\% missing data on 3-month outcomes were excluded from this study.

We assigned stroke etiology using clinical and radiological characteristics and International Statistical Classification of Diseases and Related Health Problems version 10 (ICD-10) diagnosis, employing the criteria for stroke etiology from the
TOAST definitions, ${ }^{1}$ based on steps that have previously been described. ${ }^{19}$ We defined stroke etiology as LAA if the presence of a stenosis was observed during radiological examination at baseline, or if significant stenosis was observed during conventional angiography. Additionally, if no information on stenosis was available, we still defined stroke etiology as LAA if the patient was given an ICD-10 diagnosis of I63.0 (cerebral infarction due to thrombosis of precerebral arteries) or 163.3 (cerebral infarction due to thrombosis of cerebral arteries). We defined stroke etiology as CE if a patient had a known atrial fibrillation or the presence of atrial fibrillation was observed at baseline, 24 hours, discharge, or by 3 months. Additionally, if no information on atrial fibrillation was available, we still defined stroke etiology as CE if the patient was given an ICD-10 diagnosis of I63.4 (cerebral infarction due to embolism of cerebral arteries). Finally, if patients fulfilled both a LAA and CE according to our criteria, we defined those patient as having multiple etiologies, and excluded them from the analyses of the specific etiologies.

\section{Outcomes}

The primary outcome was successful reperfusion after EVT treatment, defined as a score of 2b-3 according to the modified Treatment in Cerebral Infarction (mTICl) sale. ${ }^{20}$ The assessment of $\mathrm{mTICl}$ score was performed locally at study center. The mTICl scale is defined as: no perfusion (0); antegrade reperfusion past the initial occlusion, but limited distal branch filling with little or slow distal reperfusion (1); antegrade reperfusion of less than half of the occluded target artery previously ischemic territory (2a); antegrade reperfusion of more than half of the occluded target artery previously ischemic territory (2b); complete antegrade reperfusion of the previously occluded target artery ischemic territory, with absence of visualized occlusion in all distal branches (3).

Secondary outcomes were: complete reperfusion defined as mTICl 3, functional independence defined by a modified Ranking Scale (mRS) score ${ }^{21}$ of $0-2$ at 3 months, death within 3 months, SICH defined by the modified SITS Monitoring Study (SITS-MOST) criteria at the 24-hour control radiological examination (defined as a local or remote parenchymal hemorrhage type 2 or any subarachnoid hemorrhage on radiological findings on follow-up radiology at 22 to 36 hours post-stroke, in 
combination with a neurological deterioration $\geq 4$ NIHSS-points or leading to death within 24 hours), number of EVT maneuvers, and procedural length of EVT (defined as arterial puncture to end of procedure time).

\section{Statistical analysis}

Baseline and demographic characteristics were presented with univariate analysis, comparing patients with LAA to patients with CE. Continuous variables were analyzed using Student's t-test, while ordinal and categorical variables were analyzed using Mann-Whitney's U test and Pearson's chi-square test, respectively. For analyzing the dichotomous outcome parameters, multivariable logistic regression models were used with CE patients as reference. Variables included into the regression models were chosen if they showed a potential confounding effect according to direct acyclic graphs. ${ }^{22}$ The variables included were: age, sex, hypertension, history of hyperlipidemia, history of diabetes mellitus, history of congestive heart failure, and history of smoking. For the continuous outcome parameters, Poisson regression models were used and adjusted for the same covariates as the logistic regression models. We performed secondary analyses by dichotomizing the study population based on (1) IVT treatment or not; (2) anterior or posterior circulation; and (3) more than two EVT maneuvers or not, where significance of $P$-values for interaction were tested for the subgroups. Statistical significance was defined as $P<0.05$. All analyses were performed in R v3.5.0 (https://cran.r-project.org).

\section{Meta-analysis}

The systematic review and meta-analysis was registered in the International prospective registry of systematic reviews PROSPERO (ID 167447). The meta-analysis followed Meta-Analysis of Observational Studies in Epidemiology (MOOSE) guidelines. The inclusion criteria for the meta-analysis were as follows: (1) published online or in print before February 3, 2020; (2) written in the English language; (3) published in peer-reviewed journal as an original scientific manuscript and based on a randomized controlled trial or observational data (both prospective and retrospective); (4) at minimum data on stroke etiology and one of the following outcomes: mTICl 2b-3, mRS 0-2 at 3 months, death by 3 months, and SICH by any definition. We allowed for one exception of rule \#3, and that was the SITS registry which is presented in this manuscript.

The screening of studies for the meta-analysis was performed by one investigator (M.M.) who searched the titles and abstracts of studies in two databases of medical publications: PubMed, Web of Science and EMBASE. The search terms used were: (((stroke OR ischemic stroke OR ischaemic stroke)) AND thrombectomy) AND (etiology OR etiologies OR subtype OR subtypes). Eligible studies were further screened with full-text reads by two investigators (M.M. and C.C.) for inclusion into the meta-analysis. Additionally, the references of the eligible studies were screened for any additional publications that could be included into the meta-analysis. If two or more studies had data that could overlap the study with the highest number of patients was included. Any inconsistencies between investigators were resolved after discussing the studies in question with a senior investigator (N.A.). Baseline and demographic characteristics in addition to outcome measurements were recorded during screening. Measurements that were presented as median and interquartile range were converted to mean and standard deviation, based on the assumption of a log-normal distribution of the original measures. ${ }^{23}$ Publication bias was checked using Egger's test and Funnel plots. Risk of bias in the included studies was assessed using the Newcastle-Ottawa Scale for observational studies and Cochrane risk of bias tool for randomized trials. In order to maintain power, all eligible studies were included in the meta-analysis.

A random-effects meta-analysis was performed on the data from the included studies. Aggregate data was recorded for all studies. If it was not possible to extract all the necessary data from the manuscripts, the corresponding authors were contacted in order to receive the aggregated data. Tau estimators were calculated using the Sidik-Jonkman method, with the confidence interval (Cl) calculated using Knapp-Hartung adustments. Forest plots were presented for the outcome variables. In order to attempt to correct for confounding effects on study-level differences, multiple meta-regression was performed. We used the same covariates as in our regression analyses for the meta-regression. All covariates that had data from at least 10 studies were included into the regression model. Aggregate data included in the meta-analysis is shown in supplementary data (Supplementary data 1).

\section{Ethical committee approval}

The current study was approved by the Stockholm Regional Ethical board through the framework of SITS-Monitoring Study II (approval number 2015/767-31). Ethical approval or written patient consent for participation in SITS differed among participating countries. Ethical approval or patient consent were obtained in countries that required this, while other countries approved the register for conduct as an anonymized audit.

Ethical and other approvals for sharing the aggregate data for the meta-analyses was the responsibility of the principle investigators of the studies asked to provide data. 


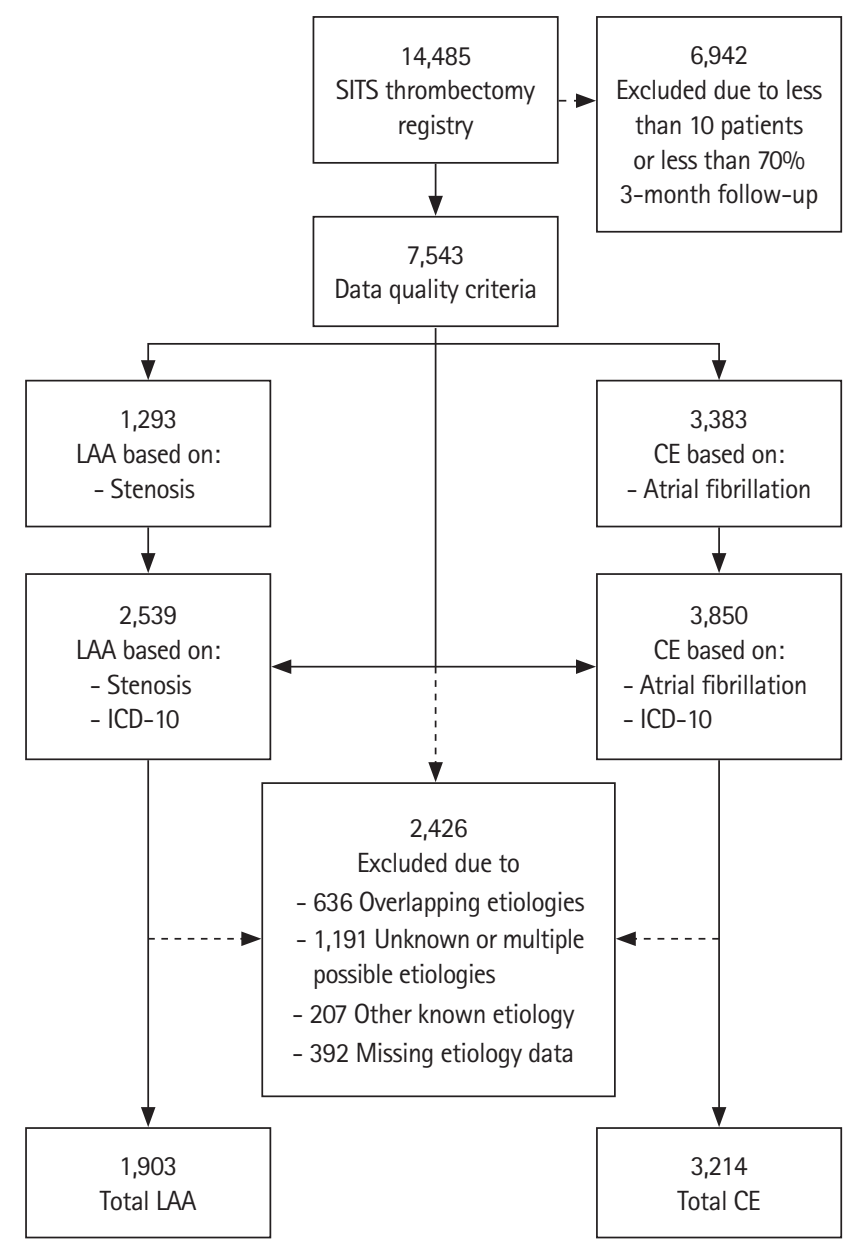

Figure 1. Study flow chart. SITS, Safe Implementation of Treatment in Stroke; LAA, large artery atherosclerosis; CE, cardiac emboli; ICD-10, International Statistical Classification of Diseases and Related Health Problems version 10.

\section{Results}

In the SITS thrombectomy database, 14,485 patients were recorded during the study period, with 7,543 patients (52.1\%) fulfilling our data quality criteria (Figure 1). After applying our criteria for stroke etiology we found 1,903 patients with LAA and 3,214 patients with CE.

Baseline and demographic characteristics are presented in Table 1. Patients with LAA were younger than CE patients, were more often men, and presented with lower NIHSS at baseline. IVT treatment was more often given to LAA patients than CE patients. Patients with LAA had longer onset to arterial puncture time that patients with CE (Supplementary Table 1).

In the univariate analyses, patients with LAA were less likely to achieve $\mathrm{mTICl} 2 b-3, \mathrm{mTICl} 3$, and $\mathrm{mRS} 0-2$ than patients with CE (Table 2). No statistically significant difference was seen death by 3 months and $\mathrm{SICH}$ when comparing patients with LAA to patients with CE.

In the multivariable logistic regression analyses, patients with LAA had lower odds of achieving successful reperfusion compared to CE patients (Table 3). Additionally, LAA patients had lower odds of functional independence and a higher risk of death, compared to CE patients. There was no difference in risk of SICH per modified SITS-MOST definition. IVT treatment showed a significant interaction for $\mathrm{mTICl} 3, \mathrm{mRS} 0-2$ and death by 3 months. Circulation area showed a significant interaction for mRS 0-2 and death by 3 months. Having more than two EVT maneuvers showed a significant interaction for all outcomes except SICH by mSITS.

The Poisson regression models showed an increase in EVT procedural time for LAA patients as compared to CE patients for all patients, while LAA patients had fewer EVT maneuvers than CE patients (Table 4). IVT treatment showed a significant interaction for both outcomes, while circulation area only showed a significant interaction for EVT procedural time.

\section{Meta-analysis}

We found 25 studies in the literature search that fit the criteria and could provide data for the meta-analysis (Supplementary Figure 1)..$^{14,15,24-46}$ The studies varied in study population sizes, from 19 to 1,134 patients with LAA or CE (Table 5). All studies that were included had an observational study design. In the risk of bias assessment, most studies fulfilled all or most of the criteria for selection and outcome while many studies did not fulfill the comparability criteria (Supplementary Table 2). The meta-analyses did not show any significant results for any of the outcomes with the unadjusted aggregate data (Figure 2). Heterogeneity between studies was moderate for the results of $\mathrm{mTI}-$ $\mathrm{Cl} 2 \mathrm{~b}-3$ and death $\left(\mathrm{I}^{2}=41 \%, \mathrm{I}^{2}=42 \%\right.$, respectively), high for the results of $\mathrm{mRS} 0-2\left(I^{2}=75 \%\right)$, and low for $\mathrm{SICH}\left(\mathrm{I}^{2}=9 \%\right)$. Nine studies ${ }^{14,15,24-30}$ had aims that largely resembled that of our meta-analysis, while the remaining studies had other aims but still had the required data for the meta-analysis. There was no publication bias as per Egger's test for $\mathrm{mTICl} 2 b-3(P=0.882), \mathrm{mRS}$ $0-2$ at 3 months $(P=0.377)$, death by 3 months $(P=0.902)$, and $\mathrm{SICH}(P=0.298)$. The funnel plots did not show major signs of asymmetry, but the results for death at 3 months and $\mathrm{SICH}$ showed S-shaped distributions of studies (Supplementary Figure 2).

The meta-regression included all planned covariates for the analysis of all of the outcomes. For $\mathrm{mTICl}$, meta-regression model was not significant $\left(F_{7,4}=0.30, P=0.919\right)$ with no significant differences on study-level. The analysis of 3-month $\mathrm{mRS}$ 0-2 found that history of smoking showed a trend for association with the meta-analysis $(P=0.061)$, but the meta-regression 
Table 1. Baseline and demographic characteristics of the study population by LAA and CE etiology

\begin{tabular}{|c|c|c|c|c|}
\hline Characteristic & LAA & CE & $P$ & $\begin{array}{l}\text { Unknown, other } \\
\text { or multiple etiology }\end{array}$ \\
\hline Number & 1,903 & 3,214 & & 2,426 \\
\hline Age & $66.1 \pm 12.6$ & $74.1 \pm 11.8$ & $<0.001$ & $68.3 \pm 14.3$ \\
\hline Systolic blood pressure, baseline & $152.4 \pm 26.2$ & $149.7 \pm 24.8$ & 0.001 & $148.6 \pm 26.3$ \\
\hline Diastolic blood pressure, baseline & $82.1 \pm 14.7$ & $81.5 \pm 16.3$ & 0.209 & $81.2 \pm 15.9$ \\
\hline Glucose, baseline (mmol/L) & $7.6 \pm 14.7$ & $7.5 \pm 16.3$ & 0.379 & $7.4 \pm 15.9$ \\
\hline Cholesterol, baseline ( $\mathrm{mmol} / \mathrm{L})$ & $4.8 \pm 3.1$ & $4.3 \pm 1.7$ & $<0.001$ & $4.5 \pm 1.1$ \\
\hline NIHSS, baseline & $15(10-20)$ & $16(12-20)$ & $<0.001$ & $16(11-20)$ \\
\hline mRS, baseline & $0(0-0)$ & $0(0-1)$ & $<0.001$ & $0(0-0)$ \\
\hline Male sex & $64.4(1,226 / 1,903)$ & $44.6(1,435 / 3,214)$ & $<0.001$ & $51.4(1,246 / 2,426)$ \\
\hline Platelet inhibitors, baseline & $30.4(563 / 1,854)$ & $30.2(936 / 3,103)$ & 0.906 & $29.8(659 / 2,215)$ \\
\hline Anti-coagulants, baseline & $2.9(54 / 1,855)$ & $30.9(959 / 3,105)$ & $<0.001$ & $11.3(250 / 2,221)$ \\
\hline Anti-hypertensive, baseline & $57.2(1,062 / 1,857)$ & $77.2(2,395 / 3,103)$ & $<0.001$ & $61.3(1,362 / 2,222)$ \\
\hline Statin, baseline & $27.1(502 / 1,852)$ & $33.3(1,027 / 3,082)$ & $<0.001$ & $27.7(608 / 2,198)$ \\
\hline Anti-diabetic, baseline & $16.5(307 / 1,856)$ & $16.8(519 / 3,098)$ & 0.877 & $14.6(322 / 2,213)$ \\
\hline Hypertension, baseline & $65.7(1,231 / 1,874)$ & $76.3(2,390 / 3,131)$ & $<0.001$ & $65.1(1,458 / 2,239)$ \\
\hline Hyperlipidemia, baseline & $32.0(598 / 1,867)$ & $38.0(1,181 / 3,105)$ & $<0.001$ & $33.9(750 / 2,214)$ \\
\hline Diabetes mellitus, baseiine & $20.7(388 / 1,875)$ & $22.1(693 / 3,132)$ & 0.247 & $17.9(401 / 2,239)$ \\
\hline Smoking, baseline & $36.0(650 / 1,805)$ & $15.1(453 / 2,997)$ & $<0.001$ & $24.0(510 / 2,126)$ \\
\hline Atrial fibrillation, baseline & $0.0(0 / 1,873)$ & $57.7(1,823 / 3,159)$ & $<0.001$ & $18.5(412 / 2,230)$ \\
\hline Congestive heart failure & $4.1(76 / 1,870)$ & $16.7(520 / 3,114)$ & $<0.001$ & $9.5(213 / 2,231)$ \\
\hline Previous TIA & $4.1(76 / 1,872)$ & $3.3(103 / 3,126)$ & 0.184 & $2.9(65 / 2,232)$ \\
\hline Previous stroke & $10.8(203 / 1,875)$ & $13.9(437 / 3,133)$ & 0.002 & $10.0(223 / 2,232)$ \\
\hline Circulation anterior/posterior, anterior & $85.1(1,408 / 1,655)$ & $92.7(2,683 / 2,895)$ & $<0.001$ & $89.7(1,829 / 2,039)$ \\
\hline Circulation intracranial/extracranial, intracranial & $89.0(1,306 / 1,467)$ & $97.0(2,737 / 2,823)$ & $<0.001$ & $94.4(1,844 / 1,954)$ \\
\hline ICA & $17.5(220 / 1,257)$ & $15.3(399 / 2,607)$ & 0.090 & $16.7(290 / 1,741)$ \\
\hline M1 & $66.2(832 / 1,257)$ & $66.1(1,722 / 2,607)$ & 0.962 & $64.9(1,130 / 1,741)$ \\
\hline M2 & $15.4(193 / 1,257)$ & $17.3(452 / 2,607)$ & 0.133 & $16.9(295 / 1,741)$ \\
\hline Other occlusion location & $1.0(12 / 1,257)$ & $1.3(34 / 2,607)$ & 0.435 & $1.5(26 / 1,741)$ \\
\hline IVT treatment & $67.7(1,289 / 1,903)$ & $56.5(1,816 / 3,214)$ & $<0.001$ & $65.7(1,595 / 2,426)$ \\
\hline
\end{tabular}

Values are presented as mean \pm standard deviation, median (interquartile range), or percentage (number). $P$-values for comparisons between LAA and CE using Student's t-test, Mann-Whitney U test, and chi-square test for continuous, ordinal and categorical variables, respectively.

LAA, large artery atherosclerosis; CE, cardiac embolism; NIHSS, National Institutes of Health Stroke Scale; mRS, modified Rankin Scale; TIA, transient ischemic attack; ICA, internal carotid artery; IVT, intravenous thrombolysis.

model was not significant $\left(\mathrm{F}_{7,4}=2.58, P=0.189\right)$. The meta-regression models for death and $\mathrm{SICH}$ did not show significant effects $\left(F_{7,3}=0.28, P=0.924\right.$; and $F_{7,2}=0.57, P=0.759$, respectively).

\section{Discussion}

Our study results based on the SITS thrombectomy registry suggested that patients with LAO stroke caused by CE and treated with EVT had a higher chance of successful reperfusion compared to patients with stroke caused by LAA. This was veri- fied in both the unadjusted and adjusted analyses. CE patients also showed a higher chance of favorable functional outcome and lower mortality at 3 months in the adjusted analysis, compared to LAA patients. This was intriguing, as patients with CE presented with a higher burden of risk-factors such as a higher age and baseline NIHSS scores in addition to more frequent hypertension and hyperlipidemia than patients with LAA. Until recently, only a few small-sized or single-center studies have investigated the relationship between stroke etiology and outcomes after EVT treatment. ${ }^{14,15,24-30,47}$ Interestingly, baseline characteristics were similar to the present study, i.e. higher 
Table 2. Univariate analysis of outcomes by LAA and CE etiology

\begin{tabular}{lcccc}
\hline & LAA & CE & $P$ & Unknown, other or multiple etiology \\
\hline Number & 1,903 & 3,214 & & 2,426 \\
mTICl $2 b-3$ & $83.4(1,172 / 1,405)$ & $86.5(2,179 / 2,518)$ & 0.009 & $84.1(1,488 / 1,769)$ \\
mTICl 3 & $53.4(750 / 1,405)$ & $61.3(1,543 / 2,518)$ & $<0.001$ & $59.5(1,053 / 1,769)$ \\
mRS 0-2 at 3 months & $45.8(753 / 1,643)$ & $42.2(1,201 / 2,846)$ & 0.020 & $46.4(931 / 2,007)$ \\
Death by 3 months & $20.6(348 / 1,687)$ & $21.8(633 / 2,908)$ & 0.384 & $20.5(421 / 2,052)$ \\
SICH by mSITS & $2.3(40 / 1,720)$ & $2.8(81 / 2,911)$ & 0.397 & $2.9(58 / 2,001)$
\end{tabular}

Values are presented as percentage (number). Chi-square test was used for comparisons.

LAA, large artery atherosclerosis; CE, cardiac embolism; mTICl, Modified Treatment in Cerebral Infarction; mRS, modified Rankin Scale; SICH, symptomatic intracranial hemorrhage; mSITS, modified Safe Implementation of Treatment in Stroke.

Table 3. Adjusted odds ratios for dichotomous outcomes for LAA compared to CE

\begin{tabular}{lccccc}
\hline Variable & $\mathrm{mTICl} 2 \mathrm{~b}-3$ & $\mathrm{mTICl} 3$ & $\mathrm{mRS} 0-2$ at 3 months & Death by 3 months & SICH by mSITS \\
\hline All patients & $0.70(0.57-0.86)$ & $0.71(0.62-0.83)$ & $0.74(0.63-0.85)$ & $1.44(1.21-1.71)$ & $1.09(0.71-1.66)$ \\
IVT treated & $0.71(0.54-0.93)$ & $0.82(0.67-0.99)$ & $0.76(0.63-0.91)^{*}$ & $1.77(1.42-2.23)^{*}$ & $1.30(0.78-2.15)$ \\
Not IVT treated & $0.64(0.47-0.88)$ & $0.54(0.42-0.69)^{*}$ & $0.64(0.49-0.82)^{*}$ & $1.12(0.84-1.49)^{*}$ & $0.70(0.30-1.51)$ \\
Anterior circulation & $0.69(0.55-0.86)$ & $0.69(0.59-0.81)$ & $0.73(0.62-0.86)^{*}$ & $1.29(1.05-1.59)^{*}$ & $1.00(0.62-1.57)$ \\
Posterior circulation & $1.08(0.57-2.03)$ & $0.78(0.48-1.26)$ & $0.59(0.36-0.95)^{*}$ & $1.80(1.11-2.96)^{*}$ & $6.67(0.87-148.54)$ \\
More than 2 EVT maneuvers & $0.75(0.54-1.03)^{*}$ & $0.68(0.50-0.92)^{*}$ & $0.62(0.44-0.87)^{*}$ & $1.53(1.07-2.20)^{*}$ & $1.12(0.48-2.44)$ \\
2 or less EVT maneuvers & $0.62(0.46-0.82)^{*}$ & $0.70(0.59-0.84)^{*}$ & $0.75(0.62-0.90)^{*}$ & $1.40(1.13-1.75)^{*}$ & $1.21(0.72-2.00)$ \\
\hline
\end{tabular}

Values are presented as odds ratio (95\% confidence interval).

LAA, large artery atherosclerosis; CE, cardiac emboli; mTICl, Modified Treatment in Cerebral Infarction; mRS, modified Rankin Scale; SICH, symptomatic intracranial hemorrhage; mSITS, modified Safe Implementation of Treatment in Stroke; IVT, intravenous thrombolysis; EVT, endovascular thrombectomy.

${ }^{*}$ P-interaction $<0.05$ for the subgrouping variable.

Table 4. Adjusted exponentiated log count results for number of EVT maneuvers and EVT procedural time for LAA compared to CE

\begin{tabular}{lcc}
\hline Variable & Difference in no. of EVT maneuvers & Difference in EVT procedural duration (min) \\
\hline All patients & $0.94(0.89-0.99)$ & $1.36(1.35-1.38)$ \\
IVT treated & $0.94(0.88-1.01)^{*}$ & $1.33(1.31-1.34)^{*}$ \\
Non-IVT treated & $0.95(0.88-1.04)^{*}$ & $1.45(1.43-1.47)^{*}$ \\
Anterior circulation & $0.94(0.89-0.997)$ & $1.38(1.37-1.40)^{*}$ \\
Posterior circulation & $1.09(0.92-1.29)$ & $1.55(1.51-1.59)^{*}$ \\
\hline
\end{tabular}

Values are presented as odds ratio (95\% confidence interval).

$\mathrm{EVT}$, endovascular thrombectomy; LAA, large artery atherosclerosis; CE, cardiac emboli; IVT, intravenous thrombolysis.

${ }^{*} P$-interaction $<0.05$ for the subgrouping variables.

age, $^{15,24-28,47}$ higher NIHSS score at baseline, ${ }^{24-28,47}$ lower proportion of males, ${ }_{1}^{15,24-26,28,47}$ and more hypertension ${ }^{15,24,26,28,47}$ for patients with CE compared to LAA.

Our results on procedural outcomes suggested that EVT procedural time was longer for patients with LAA, while also fewer EVT maneuvers were performed. Longer reperfusion time, fewer EVT maneuvers, and lower reperfusion rate may suggest that patients with LAA have a more difficult access to the occlusion site perhaps due to more complex arterial lumen due to atherosclerotic changes. Interestingly, the associations between etiology and $\mathrm{mTICl}, \mathrm{mRS} 0-2$ and death seen in the main re- sults were seemingly maintained in both those that had more than two and two or less EVT maneuvers, despite LAA patients having overall fewer EVT maneuvers. Previous studies have found similar associations to EVT maneuvers ${ }^{14,24,29}$ and procedural time, ${ }_{1}^{15,24-26}$ while some studies found no difference in EVT maneuvers ${ }^{15,25}$ and procedural time, ${ }_{1}^{28}$ or shorter procedural times for patients with LAA. ${ }^{14,29}$ Notably, only one previous study performed adjusted analysis on EVT maneuvers and procedural time. $^{15}$

Despite similar baseline characteristics comparing our patient cohort and the patients included in previous studies, the out- 
Table 5. Summary of studies included in the meta-analysis

\begin{tabular}{|c|c|c|c|c|c|c|c|}
\hline Study & Country & No. of LAA & No. of CE & $\mathrm{mTICl} 2 \mathrm{~b}-3$ & mRS $0-2$ at 3 months & Death by 3 months & SICH by study criteria \\
\hline Present study & International & 1,903 & 3,214 & $3,351 / 3,925$ & $1,954 / 4,489$ & $981 / 4,595$ & $121 / 4,510$ \\
\hline Sun et al. $(2019)^{24}$ & China & 309 & 340 & $544 / 649$ & $279 / 649$ & $166 / 649$ & $104 / 649$ \\
\hline Guglielmi et al. (2019) ${ }^{15}$ & Netherlands & 190 & 476 & $357 / 656$ & $230 / 606$ & $182 / 608$ & $35 / 666$ \\
\hline Garcia-Bermejo et al. (2019) ${ }^{31}$ & Quatar & 45 & 44 & $75 / 89$ & $22 / 50$ & $1 / 38$ & $2 / 81$ \\
\hline Deng et al. (2019) ${ }^{25}$ & China & 35 & 46 & $79 / 81$ & $45 / 81$ & $8 / 81$ & $2 / 81$ \\
\hline Baik et al. $(2019)^{30}$ & South Korea & 48 & 34 & $64 / 82$ & $30 / 82$ & $17 / 82$ & $5 / 82$ \\
\hline Yoshimura et al. (2018) ${ }^{33}$ & Japan & 197 & 937 & $509 / 1,134$ & $467 / 1,134$ & $94 / 1,134$ & $29 / 1,134$ \\
\hline Sharma et al. $(2018)^{34}$ & USA & 24 & 24 & $37 / 48$ & $16 / 48$ & $10 / 48$ & $8 / 48$ \\
\hline Maekawa et al. (2018) & Japan & 5 & 30 & $34 / 35$ & $13 / 35$ & $4 / 35$ & $1 / 35$ \\
\hline Luo et al. $(2018)^{36}$ & China & 63 & 6 & - & $25 / 69$ & - & - \\
\hline Lee et al. $(2018)^{26}$ & South Korea & 90 & 421 & $411 / 520$ & $274 / 520$ & - & - \\
\hline Imahori et al. $(2019)^{27}$ & Japan & 11 & 39 & $45 / 50$ & $24 / 50$ & $3 / 50$ & $1 / 50$ \\
\hline Gory et al. (2018) $)^{32}$ & France & 33 & 39 & $60 / 72$ & $24 / 70$ & $30 / 70$ & - \\
\hline Díaz-Pérez (2018) ${ }^{37}$ & Spain & 62 & 52 & $101 / 114$ & $33 / 114$ & $30 / 114$ & $7 / 114$ \\
\hline Berndt et al. (2018) & Germany & 12 & 52 & $56 / 64$ & $13 / 28$ & $6 / 28$ & - \\
\hline Wen et al. $(2017)^{39}$ & China & 8 & 11 & $17 / 19$ & $10 / 19$ & $1 / 19$ & - \\
\hline Uno et al. $(2017)^{40}$ & Japan & 6 & 27 & - & $19 / 33$ & - & - \\
\hline Park et al. $(2017)^{41}$ & South Korea & 141 & 359 & $360 / 500$ & $184 / 500$ & $86 / 500$ & $46 / 500$ \\
\hline Giray et al. $(2017)^{14}$ & Turkey & 19 & 33 & $32 / 52$ & $24 / 49$ & $13 / 52$ & $3 / 52$ \\
\hline Bouslama et al. $(2017)^{42}$ & USA & 61 & 65 & - & $81 / 146$ & - & - \\
\hline Boeckh-Behrens et al. (2016) ${ }^{29}$ & Germany & 22 & 67 & - & $15 / 43$ & $10 / 43$ & - \\
\hline Angermaier et al. $(2016)^{43}$ & Germany & 10 & 37 & $31 / 47$ & - & - & - \\
\hline Ahn et al. $(2016)^{44}$ & South Korea & 8 & 22 & - & $11 / 30$ & - & - \\
\hline Yoon et al. $(2015)^{28}$ & South Korea & 64 & 80 & $122 / 144$ & $72 / 144$ & $18 / 144$ & $5 / 144$ \\
\hline Wong et al. $(2013)^{45}$ & China & 7 & 14 & $14 / 21$ & $8 / 18$ & $5 / 18$ & $2 / 18$ \\
\hline Soize et al. $(2013)^{46}$ & France & 5 & 28 & - & $19 / 33$ & - & - \\
\hline
\end{tabular}

LAA, large artery atherosclerosis; CE, cardiac embolism; mTICI, Modified Treatment in Cerebral Infarction; mRS, modified Rankin Scale; SICH, symptomatic intracranial hemorrhage.

comes varied between the aforementioned studies. Most studies only presented unadjusted analyses, where two studies found that successful reperfusion was more common with CE patients as compared to LAA patients, ${ }_{1}^{27,47}$ one study found the opposite association ${ }_{1}^{28}$ while the remaining studies did not find any difference. ${ }^{14,15,24-26,30}$ On the other hand, these studies showed results favoring LAA over CE regarding functional independence at 3 months, with no studies favoring CE for 3-month mortality or $\mathrm{SICH}^{14,15,24-30}$ This was also true for the meta-analysis, in which no significant difference was found between the etiologies regarding the outcomes in the unadjusted results.

Studies that did report the adjusted analyses showed interesting results. A few studies did not find any significant differences in reperfusion or clinical outcomes between patients with LAA and CE. ${ }^{14,15,26,28,47}$ Two of these studies showed no difference in functional independence ${ }^{14,15}$ and one study detected no difference in successful reperfusion. ${ }^{15}$ However, for studies that did find a significant difference, this was mostly in favor of CE patients, one study finding a higher chance for successful reperfusion, ${ }^{26}$ and a brief report finding a higher chance for functional independence. ${ }^{47}$ Interestingly, a mediation analysis showed that almost half of the improved functional independence in CE patients was explained by achieving successful reperfusion ${ }_{1}^{47}$ illustrating the relationship between stroke etiology, reperfusion status, and functional independence. Two other studies found similar results, favoring CE patients over LAA patients for successful reperfusion, functional independence and death, after multivariate adjustment. ${ }^{26,28}$ Considering that the baseline characteristics did not favor patients with $\mathrm{CE}$, these contradictory results highlight the risk of focusing on unadjusted results. Our meta-analysis is based on unadjusted aggregate data, and we found no difference between etiolo- 


\begin{tabular}{|c|c|c|}
\hline \multirow[b]{2}{*}{ Study } & \multicolumn{2}{|c|}{ LAA } \\
\hline & Events & Total \\
\hline Matusevicius 2020 & 1,172 & 1,405 \\
\hline Sun B 2019 & 261 & 309 \\
\hline Guglielmi 2019 & 96 & 186 \\
\hline Garcia-Bermejo 2019 & 39 & 45 \\
\hline Deng 2019 & 34 & 35 \\
\hline Baik 2019 & 35 & 48 \\
\hline Yoshimura 2018 & 95 & 197 \\
\hline Sharma 2018 & 15 & 24 \\
\hline Maekawa 2018 & 5 & 5 \\
\hline Luo 2018 & - & - \\
\hline Lee 2018 & 76 & 99 \\
\hline Inahori 2018 & 7 & 11 \\
\hline Gory 2018 & 25 & 33 \\
\hline Diaz-Perez 2018 & 55 & 62 \\
\hline Berndt 2018 & 11 & 12 \\
\hline Wen 2017 & 7 & 8 \\
\hline Uno 2017 & - & - \\
\hline Park 2017 & 100 & 141 \\
\hline Giray 2017 & 15 & 19 \\
\hline Bouslama 2017 & - & - \\
\hline Boeckh-Behrens 2016 & - & - \\
\hline Angermaier 2016 & 8 & 10 \\
\hline Ahn 2016 & - & - \\
\hline Yoon 2015 & 59 & 64 \\
\hline Wong 2013 & 3 & 7 \\
\hline Soize 2013 & - & - \\
\hline Random effects model & & \\
\hline Heterogeneity: $\left.\right|^{2}=41 \%$ & $08, P=$ & \\
\hline
\end{tabular}

$\mathrm{mTICl} 2 \mathrm{~b}-3$

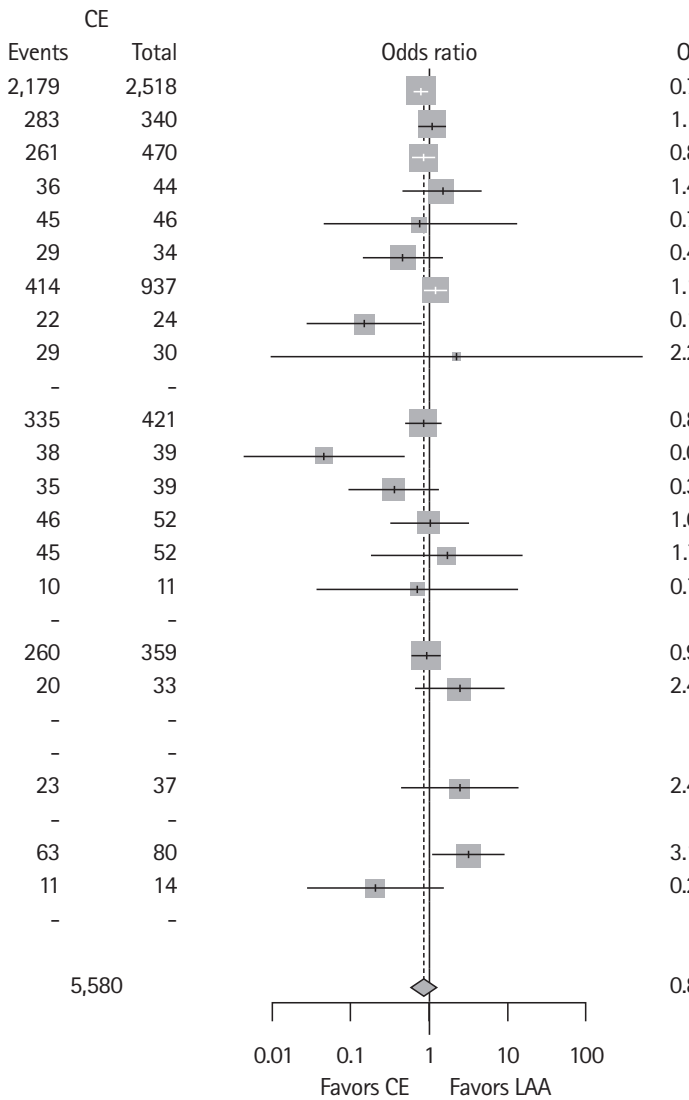

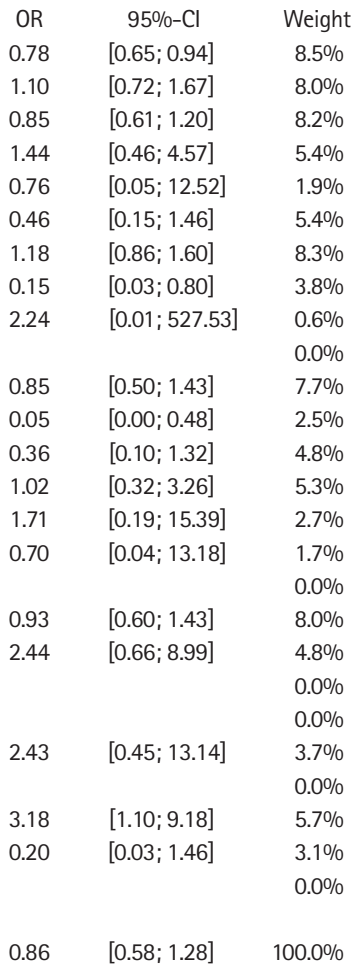

A

\begin{tabular}{|c|c|c|}
\hline \multirow[b]{2}{*}{ Study } & \\
\hline & Events & LAA Total \\
\hline Matusevicius 2020 & 753 & 1,643 \\
\hline Sun B 2019 & 155 & 309 \\
\hline Guglielmi 2019 & 80 & 175 \\
\hline Garcia-Bermejo 2019 & 9 & 22 \\
\hline Deng 2019 & 26 & 35 \\
\hline Baik 2019 & 12 & 48 \\
\hline Yoshimura 2018 & 78 & 197 \\
\hline Sharma 2018 & 7 & 24 \\
\hline Maekawa 2018 & 1 & 5 \\
\hline Luo 2018 & 22 & 63 \\
\hline Lee 2018 & 45 & 99 \\
\hline Inahori 2018 & 6 & 11 \\
\hline Gory 2018 & 11 & 33 \\
\hline Diaz-Perez 2018 & 16 & 62 \\
\hline Berndt 2018 & 6 & 7 \\
\hline Wen 2017 & 1 & 8 \\
\hline Uno 2017 & 3 & 6 \\
\hline Park 2017 & 60 & 141 \\
\hline Giray 2017 & 12 & 17 \\
\hline Bouslama 2017 & 16 & 61 \\
\hline Boeckh-Behrens 2016 & 5 & 6 \\
\hline Angermaier 2016 & - & - \\
\hline Ahn 2016 & 2 & 8 \\
\hline Yoon 2015 & 36 & 64 \\
\hline Wong 2013 & 3 & 7 \\
\hline Soize 2013 & 2 & 5 \\
\hline Random effects model & & \\
\hline Heterogeneity: $\mathrm{I}^{2}=750$ & & \\
\hline
\end{tabular}

CE

mRS $0-2$ at 3 months

\begin{tabular}{|c|c|}
\hline Events & CE Total \\
\hline 1,201 & 2,846 \\
\hline 124 & 340 \\
\hline 150 & 431 \\
\hline 13 & 28 \\
\hline 19 & 46 \\
\hline 18 & 34 \\
\hline 389 & 937 \\
\hline 9 & 24 \\
\hline 12 & 30 \\
\hline 3 & 6 \\
\hline 229 & 421 \\
\hline 18 & 39 \\
\hline 13 & 37 \\
\hline 17 & 52 \\
\hline 7 & 21 \\
\hline 9 & 11 \\
\hline 16 & 27 \\
\hline 124 & 359 \\
\hline 12 & 32 \\
\hline 65 & 85 \\
\hline 10 & 37 \\
\hline- & - \\
\hline 9 & 22 \\
\hline 36 & 80 \\
\hline 5 & 11 \\
\hline 17 & 28 \\
\hline \multicolumn{2}{|c|}{5,984} \\
\hline
\end{tabular}

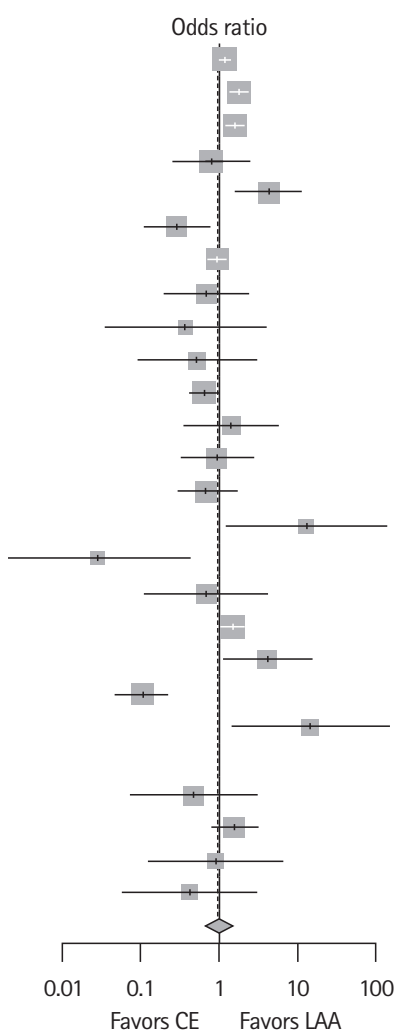

$\begin{array}{rcr}\text { OR } & 95 \%-\mathrm{Cl} & \text { Weight } \\ 1.16 & {[1.03 ; 1.31]} & 5.5 \% \\ 1.75 & {[1.28 ; 2.40]} & 5.4 \% \\ 1.58 & {[1.10 ; 2.26]} & 5.3 \% \\ 0.80 & {[0.26 ; 2.47]} & 4.2 \% \\ 4.11 & {[1.57 ; 10.71]} & 4.5 \% \\ 0.30 & {[0.12 ; 0.76]} & 4.5 \% \\ 0.92 & {[0.67 ; 1.26]} & 5.4 \% \\ 0.69 & {[0.21 ; 2.30]} & 4.0 \% \\ 0.38 & {[0.04 ; 3.78]} & 2.3 \% \\ 0.54 & {[0.10 ; 2.88]} & 3.2 \% \\ 0.70 & {[0.45 ; 1.08]} & 5.3 \% \\ 1.40 & {[0.37 ; 5.37]} & 3.8 \% \\ 0.92 & {[0.34 ; 2.48]} & 4.4 \% \\ 0.72 & {[0.32 ; 1.61]} & 4.7 \% \\ 12.00 & {[1.20 ; 120.08]} & 2.3 \% \\ 0.03 & {[0.00 ; 0.43]} & 2.0 \% \\ 0.69 & {[0.12 ; 4.06]} & 3.1 \% \\ 1.40 & {[0.94 ; 2.09]} & 5.3 \% \\ 4.00 & {[1.13 ; 14.17]} & 3.9 \% \\ 0.11 & {[0.05 ; 0.23]} & 4.8 \% \\ 13.50 & {[1.40 ; 13.019]} & 2.4 \% \\ & & 0.0 \% \\ 0.48 & {[0.08 ; 2.95]} & 3.0 \% \\ 1.57 & {[0.81 ; 3.05]} & 5.0 \% \\ 0.90 & {[0.13 ; 6.08]} & 2.9 \% \\ 0.43 & {[0.06 ; 3.01]} & 2.8 \% \\ 0.95 & {[0.61 ; 1.50]} & 100.0 \% \\ & & \\ & & \\ 0.50\end{array}$

Figure 2. Meta-analysis of included studies for the outcomes, with aggregate, unadjusted data. (A) Modified Treatment in Cerebral Infarction (mTICl) 2b-3, (B) modified Rankin Scale (mRS) 0-2 at 3 months, (C) death by 3 months, and (D) symptomatic intracranial hemorrhage (SICH). LAA, large artery atherosclerosis; $\mathrm{CE}$, cardiac emboli; $\mathrm{OR}$, odds ratio; $\mathrm{Cl}$, confidence interval. 


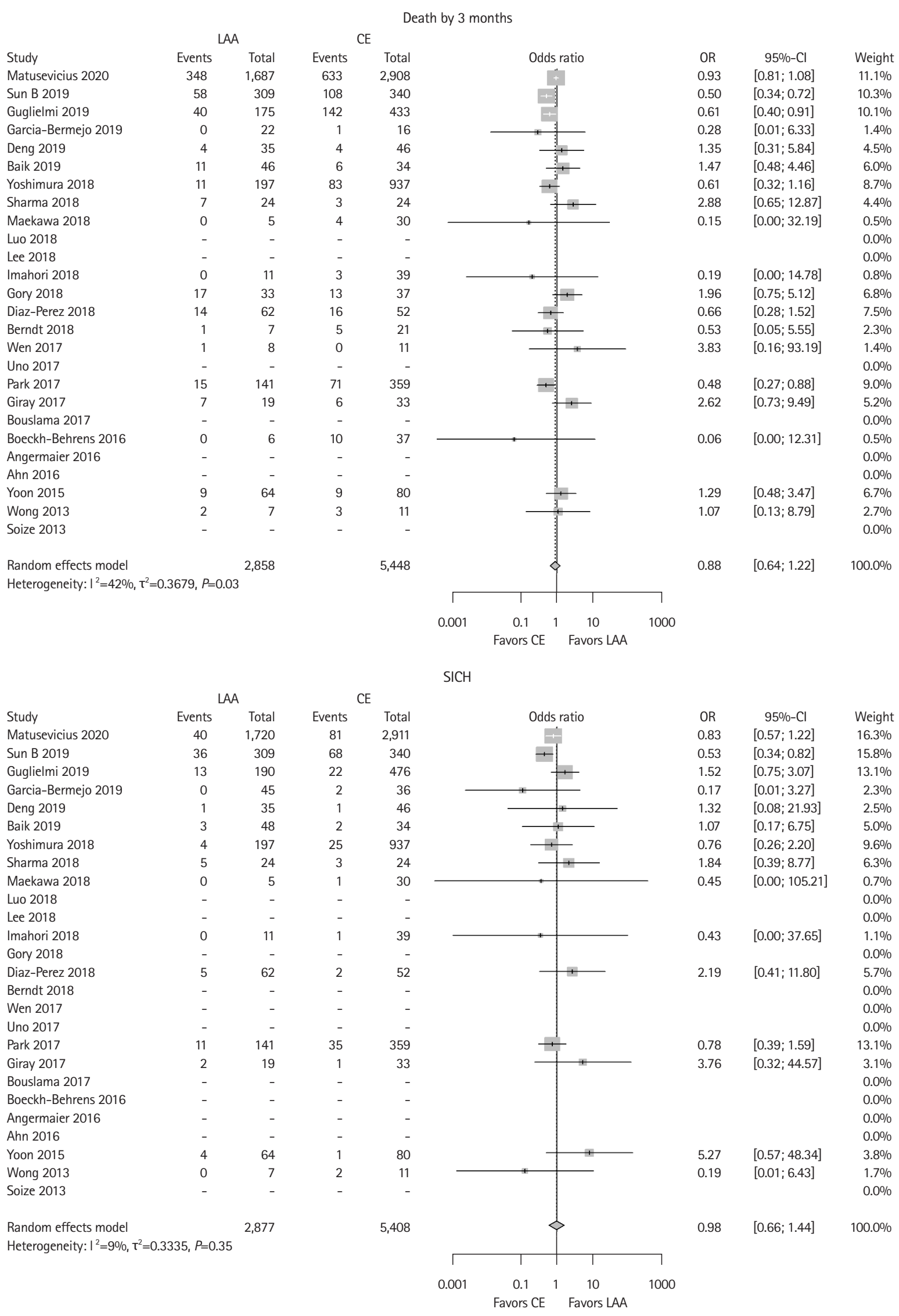

Death by 3 months

Figure 2. Continued. 
gies. While some previous studies suggest a potential benefit for patients with LAA in unadjusted results, this association was inverted after adjustment in both our SITS-thrombectomy database and several other studies. ${ }^{26,47}$ A similar effect could potentially be seen in the studies only reporting unadjusted results, highlighting the necessity of adjustment for known confounders and cautious interpretation of unadjusted results. Important to note however, we did not find any significant association with the covariates on a study-level in our meta-regression. Our results from the meta-analysis and meta-regression further emphasize the need for more in-depth analysis of stroke etiology and its association with outcomes after EVT. A meta-analysis of individual participant data is much needed.

\section{Clinical implications}

Despite data suggesting that stroke etiology may affect reperfusion and outcomes after EVT, it is still unclear how this knowledge could be transferred to the acute setting. Thrombi composition and associated underlying vascular changes, such as stenosis, may be reasons for differences in EVT outcomes between LAA and CE patients. Historically, LAA and CE thrombi have been categorized as white and red thrombi, respectively. ${ }^{3,4}$ Yet a meta-analysis of thrombi composition only found a trend towards this association. ${ }^{48}$ The main issue is that stroke etiology is not known before EVT treatment. However, radiological signs such as hyperdense artery sign in the non-contrast computed tomography could suggest the content of the thrombus. $^{49,50}$ The possibility of radiologically differentiating stroke etiology was further suggested by a recent consensus statement. ${ }^{51}$ If this were to be confirmed in future studies, the information on etiology could be used for procedural choices given the difference in procedural outcomes based on stroke etiology. Currently, very limited data exists on etiology playing a significant role in procedural choices. One study found a trend for converting stent-retriever approach to aspiration with fibrin-rich thrombi, ${ }^{35}$ while other studies suggested that LAA thrombi had a lower chance of complete reperfusion on first pass ${ }^{15}$, or more pre-interventional clot migration..$^{52}$ Additionally, fibrin rich thrombi with low erythrocyte percentage were associated with less successful reperfusion and higher risk of secondary embolism ${ }_{1}^{49}$ while red blood cell rich thrombi where associated with fewer EVT maneuvers. ${ }^{35}$ Combined, these results would suggest procedural differences based on thrombus composition and therefore etiology, with LAA thrombi requiring more demanding interventions and higher risk of secondary embolism.

Our study has some limitations. Firstly, the retrospective observational design may have led to unintended bias and an in- ability to correct for unknown confounders. Secondly, we could not validate or fill in any missing clinical or imaging data from the study centers due to the international multi-center setting of the SITS registry. This could potentially bias our results due to the missing data. For the vast majority of cases, we relied on ICD-10 diagnoses which are set by clinicians and added to the database. Despite the information and support provided by the SITS registry in guiding physicians to use the most recent guidelines when diagnosing etiology, this may lead to differences between clinicians as well as centers. Thirdly, almost a quarter of our patients had unspecified or unknown etiologies, which may have affected our results. Fourthly, our definition of LAA, similarly to the TOAST definition, did not differentiate in situ-occlusion from artery-to-artery embolism. This differentiation was not available in the SITS registry, which may influence our results. Finally, as the meta-analysis used unadjusted aggregate data, there is a risk that potential confounders may have affected the results.

\section{Conclusions}

In this study based on SITS thrombectomy registry data, we observed a lower chance of successful reperfusion and worse 3-month outcome after EVT for patients with LAA compared to CE after adjusting for known confounders, despite presenting with fewer risk-factors at baseline. In contrast, our meta-analysis based on unadjusted aggregate data did not find any difference in outcomes between etiologies. A meta-analysis of individual participant data is much needed.

\section{Supplementary materials}

Supplementary materials related to this article can be found online at https://doi.org/10.5853/jos.2021.00850.

\section{Disclosure}

Niaz Ahmed is the Chairman and Tiago Moreira is a research executive at SITS International, which receives a grant from Boehringer Ingelheim for the SITS-International Stroke Thrombolysis Register and from Stryker, Covidien and Phenox in collaboration with Karolinska Institute for the SITS-OPEN study. The remaining co-authors do not have any relevant disclosures to present.

\section{Acknowledgments}

We thank all SITS Thrombectomy register investigators and 
their centers for their participation. We thank the SITS Scientific Committee for overseeing SITS Scientific activities. We also thank all patients who participated in SITS Thrombectomy register.

This study was funded directly or indirectly through several grants. No funding source has had any impact on the methodology or the presented results of this study. Marius Matusevicius, Charith Cooray, Tiago Moreira, Staffan Holmin, and Niaz Ahmed have received funding by the Stockholm Regional council. Marius Matusevicius, Charith Cooray, and Niaz Ahmed have received funding by the Swedish Stroke Foundation. Marius Matusevicius, Tiago Moreira, Staffan Holmin, and Niaz Ahmed have received funding by the Karolinska Institute. Staffan Holmin has received funding from the Söderberg Foundations and MedTechLabs.

\section{References}

1. Adams HP Jr, Bendixen BH, Kappelle ப, Biller J, Love BB, Gordon $\mathrm{DL}$, et al. Classification of subtype of acute ischemic stroke. Definitions for use in a multicenter clinical trial. TOAST. Trial of Org 10172 in Acute Stroke Treatment. Stroke 1993; 24:35-41.

2. Campbell BCV, De Silva DA, Macleod MR, Coutts SB, Schwamm LH, Davis SM, et al. Ischaemic stroke. Nat Rev Dis Primers 2019;5:70.

3. Mustard JF, Murphy EA, Rowsell HC, Downie HG. Factors influencing thrombus formation in vivo. Am J Med 1962;33:621647.

4. Deykin D. Thrombogenesis. N Engl J Med 1967;276:622-628.

5. Mistry EA, Mistry AM, Nakawah MO, Chitale RV, James RF, Volpi JJ, et al. Mechanical thrombectomy outcomes with and without intravenous thrombolysis in stroke patients: a meta-analysis. Stroke 2017;48:2450-2456.

6. Goyal M, Menon BK, van Zwam WH, Dippel DW, Mitchell PJ, Demchuk AM, et al. Endovascular thrombectomy after large-vessel ischaemic stroke: a meta-analysis of individual patient data from five randomised trials. Lancet 2016;387: 1723-1731.

7. Goyal M, Demchuk AM, Menon BK, Eesa M, Rempel JL, Thornton J, et al. Randomized assessment of rapid endovascular treatment of ischemic stroke. N Engl J Med 2015;372:1 019-1030.

8. Berkhemer OA, Fransen PS, Beumer D, van den Berg LA, Lingsma HF, Yoo AJ, et al. A randomized trial of intraarterial treatment for acute ischemic stroke. N Engl J Med 2015;372: $11-20$.

9. Saver JL, Goyal M, Bonafe A, Diener HC, Levy El, Pereira VM, et al. Stent-retriever thrombectomy after intravenous t-PA vs. t-PA alone in stroke. N Engl J Med 2015;372:2285-2295.

10. Campbell BC, Mitchell PJ, Kleinig TJ, Dewey HM, Churilov L, Yassi $N$, et al. Endovascular therapy for ischemic stroke with perfusion-imaging selection. N Engl J Med 2015;372:10091018.

11. Jovin TG, Chamorro A, Cobo $E$, de Miquel MA, Molina CA, Rovira $A$, et al. Thrombectomy within 8 hours after symptom onset in ischemic stroke. N Engl J Med 2015;372:2296-2306.

12. Todo K, Sakai N, Imamura H, Yamagami H, Adachi H, Kono T, et al. Successful reperfusion with endovascular therapy has beneficial effects on long-term outcome beyond 90 days. Cerebrovasc Dis 2019;47:127-134.

13. Wollenweber FA, Tiedt $S$, Alegiani A, Alber B, Bangard C, Berrouschot $J$, et al. Functional outcome following stroke thrombectomy in clinical practice. Stroke 2019;50:2500-2506.

14. Giray $S$, Ozdemir 0, Baş DF, İnanç $Y$, Arlıer $Z$, Kocaturk 0. Does stroke etiology play a role in predicting outcome of acute stroke patients who underwent endovascular treatment with stent retrievers? J Neurol Sci 2017;372:104-109.

15. Guglielmi V, LeCouffe NE, Zinkstok SM, Compagne KCJ, Eker $\mathrm{R}$, Treurniet KM, et al. Collateral circulation and outcome in atherosclerotic versus cardioembolic cerebral large vessel occlusion. Stroke 2019;50:3360-3368.

16. Tsang ACO, Orru E, Klostranec JM, Yang IH, Lau KK, Tsang FCP, et al. Thrombectomy outcomes of intracranial atherosclerosis-related occlusions. Stroke 2019;50:1460-1466.

17. Wahlgren $N$, Ahmed N, Dávalos A, Ford GA, Grond M, Hacke $W$, et al. Thrombolysis with alteplase for acute ischaemic stroke in the Safe Implementation of Thrombolysis in Stroke-Monitoring Study (SITS-MOST): an observational study. Lancet 2007;369:275-282.

18. Matusevicius M, Cooray $C$, Bottai M, Mazya M, Tsivgoulis G, Nunes AP, et al. Blood pressure after endovascular thrombectomy: modeling for outcomes based on recanalization status. Stroke 2020;51:519-525.

19. Matusevicius M, Paciaroni M, Caso V, Bottai M, Khurana D, de Bastos $M$, et al. Outcome after intravenous thrombolysis in patients with acute lacunar stroke: an observational study based on SITS international registry and a meta-analysis. Int J Stroke 2019;14:878-886.

20. Zaidat 00, Yoo AJ, Khatri P, Tomsick TA, von Kummer R, Saver $\mathrm{J}$, et al. Recommendations on angiographic revascularization grading standards for acute ischemic stroke: a consensus statement. Stroke 2013;44:2650-2663.

21. van Swieten JC, Koudstaal PJ, Visser MC, Schouten HJ, van Gijn J. Interobserver agreement for the assessment of handicap in stroke patients. Stroke 1988;19:604-607. 
22. Greenland S, Pearl J, Robins JM. Causal diagrams for epidemiologic research. Epidemiology 1999;10:37-48.

23. Wan X, Wang W, Liu J, Tong T. Estimating the sample mean and standard deviation from the sample size, median, range and/or interquartile range. BMC Med Res Methodol 2014; 14:135.

24. Sun B, Shi Z, Pu J, Yang S, Wang H, Yang D, et al. Effects of mechanical thrombectomy for acute stroke patients with etiology of large artery atherosclerosis. J Neurol Sci 2019; 396:178-183.

25. Deng $Y$, Jia B, Huo X, Peng Y, Cao Y, Chen S, et al. Association of cardioembolism and intracranial arterial stenosis with outcomes of mechanical thrombectomy in acute ischemic stroke. World Neurosurg 2019;121:e154-e158.

26. Lee JS, Lee SJ, Yoo JS, Hong JH, Kim CH, Kim YW, et al. Prognosis of acute intracranial atherosclerosis-related occlusion after endovascular treatment. J Stroke 2018;20:394-403.

27. Imahori T, Okamura Y, Sakata J, Shose H, Yokote A, Matsushima $K$, et al. Stent expansion and in-stent thrombus sign in the trevo stent retriever predict recanalization and possible etiology during mechanical thrombectomy: a case series of 50 patients with acute middle cerebral artery occlusion. World Neurosurg 2019;124:e303-e311.

28. Yoon W, Kim SK, Park MS, Kim BC, Kang HK. Endovascular treatment and the outcomes of atherosclerotic intracranial stenosis in patients with hyperacute stroke. Neurosurgery 2015;76:680-686.

29. Boeckh-Behrens T, Kleine JF, Zimmer C, Neff F, Scheipl F, Pelisek J, et al. Thrombus histology suggests cardioembolic cause in cryptogenic stroke. Stroke 2016;47:1864-1871.

30. Baik SH, Park HJ, Kim JH, Jang CK, Kim BM, Kim DJ. Mechanical thrombectomy in subtypes of basilar artery occlusion: relationship to recanalization rate and clinical outcome. $R a-$ diology 2019;291:730-737.

31. Garcia-Bermejo P, Patro SN, Ahmed AZ, Al Rumaihi G, Akhtar $\mathrm{N}$, Kamran $\mathrm{S}$, et al. Baseline occlusion angiographic appearance on mechanical thrombectomy suggests underlying etiology and outcome. Front Neurol 2019;10:499.

32. Gory B, Mazighi M, Labreuche J, Blanc R, Piotin M, Turjman $F_{1}$ et al. Predictors for mortality after mechanical thrombectomy of acute basilar artery occlusion. Cerebrovasc Dis 2018; 45:61-67.

33. Yoshimura S, Sakai N, Uchida K, Yamagami H, Ezura M, Okada $Y$, et al. Endovascular therapy in ischemic stroke with acute large-vessel occlusion: recovery by endovascular salvage for cerebral ultra-acute embolism Japan registry 2. J Am Heart Assoc 2018;7:e008796.

34. Sharma R, Llinas RH, Urrutia V, Marsh EB. Collaterals predict outcome regardless of time last known normal. J Stroke Cerebrovasc Dis 2018;27:971-977.

35. Maekawa $K$, Shibata M, Nakajima H, Mizutani A, Kitano $Y$, Seguchi $M$, et al. Erythrocyte-rich thrombus is associated with reduced number of maneuvers and procedure time in patients with acute ischemic stroke undergoing mechanical thrombectomy. Cerebrovasc Dis Extra 2018;8:39-49.

36. Luo G, Mo D, Tong $X$, Liebeskind DS, Song L, Ma N, et al. Factors associated with 90-day outcomes of patients with acute posterior circulation stroke treated by mechanical thrombectomy. World Neurosurg 2018;109:e318-e328.

37. Díaz-Pérez J, Parrilla G, Espinosa de Rueda M, Cabrera-Maqueda JM, García-Villalba B, Alba-Isasi MT, et al. Mechanical thrombectomy in acute stroke due to carotid occlusion: a series of 153 consecutive patients. Cerebrovasc Dis 2018;46: 132-141.

38. Berndt $M$, Friedrich $B$, Maegerlein $C$, Moench $S$, Hedderich D, Lehm $M$, et al. Thrombus permeability in admission computed tomographic imaging indicates stroke pathogenesis based on thrombus histology. Stroke 2018;49:2674-2682.

39. Wen WL, Li ZF, Zhang YW, Yang PF, Simfukwe $K$, Fang YB, et al. Effect of baseline characteristics on the outcome of stent retriever-based thrombectomy in acute basilar artery occlusions: a single-center experience and pooled data analysis. World Neurosurg 2017;104:1-8.

40. Uno J, Kameda K, Otsuji R, Ren N, Nagaoka S, Maeda K, et al. Mechanical thrombectomy for acute basilar artery occlusion in early therapeutic time window. Cerebrovasc Dis 2017;44: 217-224.

41. Park HK, Chung JW, Hong JH, Jang MU, Noh HD, Park JM, et al. Preceding intravenous thrombolysis in patients receiving endovascular therapy. Cerebrovasc Dis 2017;44:51-58.

42. Bouslama M, Haussen DC, Aghaebrahim A, Grossberg JA, Walker G, Rangaraju $S$, et al. Predictors of good outcome after endovascular therapy for vertebrobasilar occlusion stroke. Stroke 2017;48:3252-3257.

43. Angermaier $A$, Michel $P$, Khaw AV, Kirsch $M$, Kessler $C$, Langner $\mathrm{S}$. Intravenous thrombolysis and passes of thrombectomy as predictors for endovascular revascularization in ischemic stroke. J Stroke Cerebrovasc Dis 2016;25:2488-2495.

44. Ahn SH, Hong R, Choo IS, Heo JH, Nam HS, Kang HG, et al. Histologic features of acute thrombi retrieved from stroke patients during mechanical reperfusion therapy. Int J Stroke 2016;11:1036-1044.

45. Wong EH, Yu SC, Lau AY, Hui VS, Leung CS, Hui JW, et al. Intra-arterial revascularisation therapy for acute ischaemic stroke: initial experience in a Hong Kong hospital. Hong Kong Med J 2013;19:135-141. 
46. Soize S, Barbe C, Kadziolka K, Estrade L, Serre I, Pierot L. Predictive factors of outcome and hemorrhage after acute ischemic stroke treated by mechanical thrombectomy with a stent-retriever. Neuroradiology 2013;55:977-987.

47. Tiedt $S$, Herzberg $M$, Küpper $C$, Feil $K$, Kellert L, Dorn F, et al. Stroke etiology modifies the effect of endovascular treatment in acute stroke. Stroke 2020;51:1014-1016.

48. Brinjikji W, Duffy $S$, Burrows A, Hacke W, Liebeskind D, Majoie CBLM, et al. Correlation of imaging and histopathology of thrombi in acute ischemic stroke with etiology and outcome: a systematic review. J Neurointerv Surg 2017;9:529534.

49. Sporns PB, Hanning U, Schwindt W, Velasco A, Buerke B,

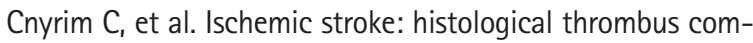

position and pre-interventional CT attenuation are associated with intervention time and rate of secondary embolism. Cerebrovasc Dis 2017;44:344-350.

50. Liebeskind DS, Sanossian N, Yong WH, Starkman S, Tsang $M P$, Moya $A L$, et al. CT and MRI early vessel signs reflect clot composition in acute stroke. Stroke 2011;42:1237-1243.

51. De Meyer SF, Andersson T, Baxter B, Bendszus M, Brouwer $P$, Brinjikji W, et al. Analyses of thrombi in acute ischemic stroke: a consensus statement on current knowledge and future directions. Int J Stroke 2017;12:606-614.

52. Sporns PB, Jeibmann A, Minnerup J, Broocks G, Nawabi J, Schön $G$, et al. Histological clot composition is associated with preinterventional clot migration in acute stroke patients. Stroke 2019;50:2065-2071. 
Supplementary Table 1. EVT procedural variables

\begin{tabular}{lcccc}
\hline Variable & LAA & CE & $P$ & Unknown, other, or multiple etiology \\
\hline Number & 1,903 & 3,214 & & 2,426 \\
Onset to arterial puncture time (min) & $314.7 \pm 242.3$ & $296.9 \pm 225.1$ & 0.013 & $308.1 \pm 239.1$ \\
EVT procedural time (min) & $77.3 \pm 53.7$ & $56.0 \pm 42.6$ & $<0.001$ & $62.3 \pm 47$ \\
No. of EVT maneuvers & $1(1-2)$ & $1(1-2)$ & 0.020 & $1(1-3)$ \\
More than 2 EVT maneuvers, yes & $24.1(390 / 1,618)$ & $24.1(673 / 2,798)$ & 0.999 & $26.7(503 / 1,887)$ \\
Primary thrombectomy device, Trevo & $27.8(443 / 1,595)$ & $30.5(848 / 2,783)$ & 0.065 & $30.6(576 / 1,880)$ \\
Primary thrombectomy device, Penumbra & $24.1(385 / 1,595)$ & $26.6(741 / 2,783)$ & 0.076 & $26.6(500 / 1,880)$ \\
Primary thrombectomy device, Solitaire & $21.4(341 / 1,595)$ & $16.3(455 / 2,783)$ & $<0.001$ & $17.6(330 / 1,880)$ \\
Secondary thrombectomy device, Trevo & $22.0(39 / 177)$ & $21.2(72 / 339)$ & 0.924 & $23.2(56 / 241)$ \\
Secondary thrombectomy device, Penumbra & $14.1(25 / 177)$ & $20.4(69 / 339)$ & 0.105 & $14.5(35 / 241)$ \\
Secondary thrombectomy device, Solitaire & $24.3(43 / 177)$ & $24.5(83 / 339)$ & 1.000 & $24.5(59 / 241)$ \\
Intracranial angioplasty & $5.9(96 / 1,618)$ & $0.6(18 / 2,798)$ & $<0.001$ & $2.5(47 / 1,887)$ \\
Extracranial angioplasty & $21.0(340 / 1,618)$ & $0.6(18 / 2,798)$ & $<0.001$ & $3.8(71 / 1,887)$ \\
Intracranial stenting & $4.8(77 / 1,618)$ & $1.0(28 / 2,798)$ & $<0.001$ & $2.9(54 / 1,887)$ \\
Extracranial stenting & $21.4(347 / 1,618)$ & $0.8(21 / 2,798)$ & $<0.001$ & $4.2(80 / 1,887)$ \\
Intraprocedural anticoagulants & $13.2(223 / 1,690)$ & $12.5(362 / 2,894)$ & 0.531 & $6.9(137 / 1,986)$ \\
Intraprocedural platelet inhibitors & $19.5(330 / 1,690)$ & $4.2(121 / 2,894)$ & $<0.001$ & $6.7(133 / 1,986)$
\end{tabular}

Values are presented as mean \pm standard deviation, median (interquartile range), or percentage (number).

$\mathrm{EVT}$, endovascular thrombectomy; LAA, large artery atherosclerosis; $\mathrm{CE}$, cardiac embolism. 
Supplementary Table 2. Risk of bias assessment of the studies included in the meta-analysisaccording to Newcastle-Ottawa quality assessment scale categories

\begin{tabular}{|c|c|c|c|c|}
\hline Study & $\begin{array}{c}\text { Selection } \\
\text { (maximum } 4 \text { points) }\end{array}$ & $\begin{array}{c}\text { Comparability } \\
\text { (maximum } 2 \text { points) }\end{array}$ & $\begin{array}{c}\text { Outcome } \\
\text { (maximum } 3 \text { points) }\end{array}$ & $\begin{array}{c}\text { Total points } \\
\text { (maximum } 9 \text { points) }\end{array}$ \\
\hline Sun et al. $(2019)^{24}$ & 4 & 0 & 3 & 7 \\
\hline Guglielmi et al. (2019) & 3 & 2 & 3 & 8 \\
\hline Garcia-Bermejo et al. (2019) & 3 & 0 & 3 & 6 \\
\hline Deng et al. (2019) ${ }^{25}$ & 3 & 1 & 3 & 7 \\
\hline Baik et al. $(2019)^{30}$ & 4 & 1 & 3 & 8 \\
\hline Yoshimura et al. (2018) ${ }^{33}$ & 3 & 0 & 3 & 6 \\
\hline Sharma et al. $(2018)^{34}$ & 3 & 0 & 3 & 6 \\
\hline Maekawa et al. $(2018)^{35}$ & 4 & 0 & 3 & 7 \\
\hline Luo et al. $(2018)^{36}$ & 4 & 1 & 3 & 8 \\
\hline Lee et al. $(2018)^{26}$ & 3 & 2 & 3 & 8 \\
\hline Imahori et al. (2019) ${ }^{27}$ & 3 & 0 & 3 & 6 \\
\hline Gory et al. $(2018)^{32}$ & 3 & 2 & 3 & 8 \\
\hline Díaz-Pérez (2018) 37 & 4 & 0 & 3 & 7 \\
\hline Berndt et al. (2018) 38 & 3 & 0 & 2 & 5 \\
\hline Wen et al. $(2017)^{39}$ & 3 & 0 & 3 & 6 \\
\hline Uno et al. $(2017)^{40}$ & 3 & 2 & 3 & 8 \\
\hline Park et al. $(2017)^{41}$ & 3 & 0 & 2 & 5 \\
\hline Giray et al. $(2017)^{14}$ & 3 & 2 & 3 & 8 \\
\hline Bouslama et al. $(2017)^{42}$ & 3 & 0 & 3 & 6 \\
\hline Boeckh-Behrens et al. (2016) ${ }^{29}$ & 3 & 0 & 2 & 5 \\
\hline Angermaier et al. (2016) ${ }^{43}$ & 3 & 0 & 3 & 6 \\
\hline Ahn et al. $(2016)^{44}$ & 3 & 0 & 3 & 6 \\
\hline Yoon et al. $(2015)^{28}$ & 4 & 0 & 3 & 7 \\
\hline Wong et al. $(2013)^{45}$ & 3 & 0 & 3 & 6 \\
\hline Soize et al. $(2013)^{46}$ & 3 & 0 & 3 & 6 \\
\hline
\end{tabular}




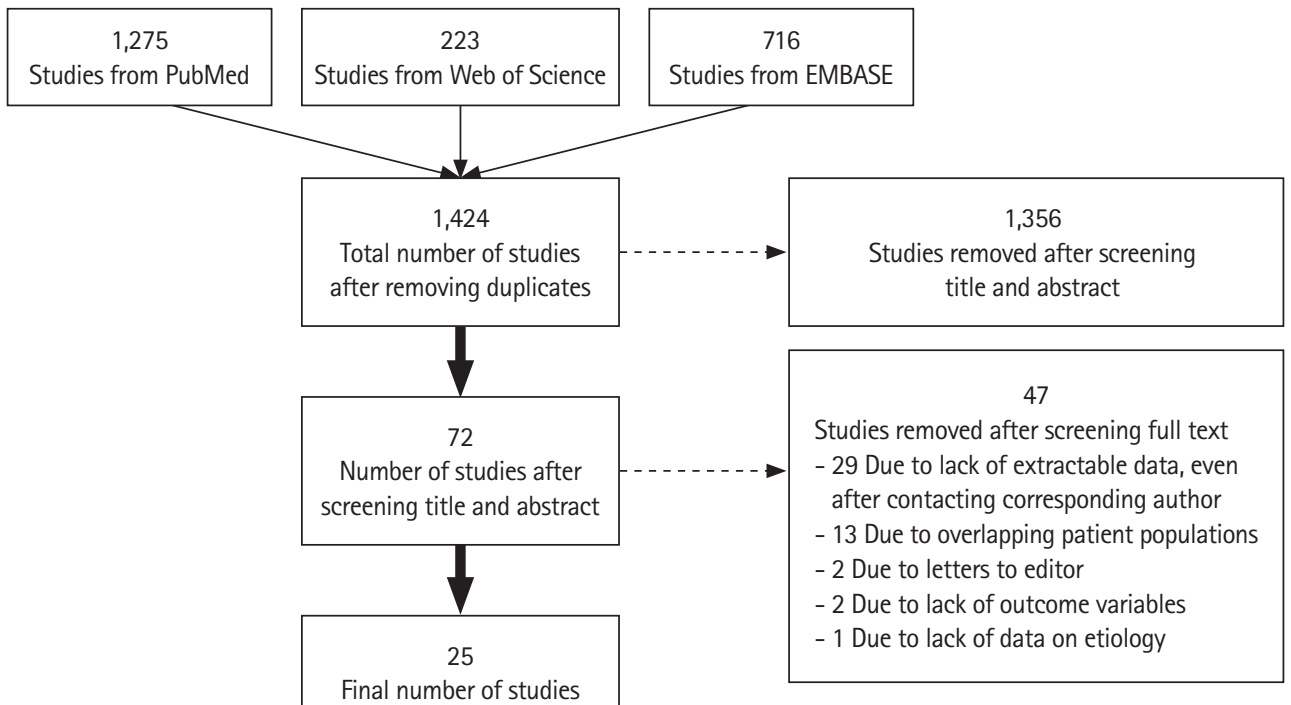

included in meta-analysis

Supplementary Figure 1. Flow chart of study selection for meta-analysis, inaccordance with Preferred Reporting Items for Systematic Reviews and Meta-Analyses (PRISMA) guidelines.

mTICl 2b-3

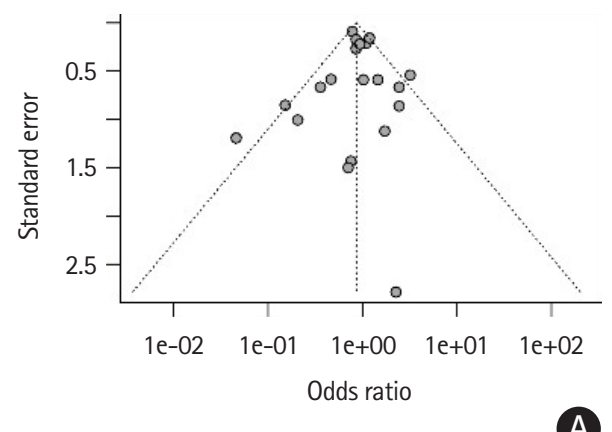

Death at 3 months

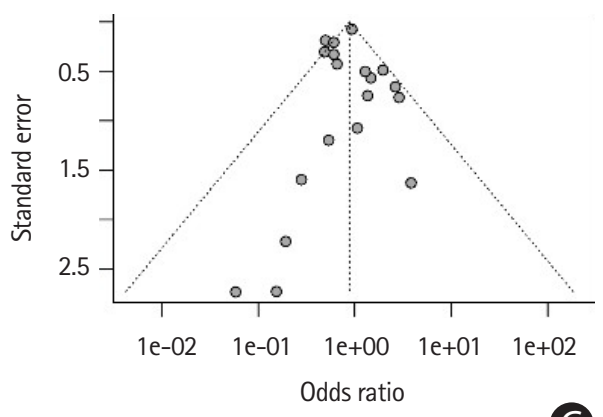

mRS $0-2$ at 3 months

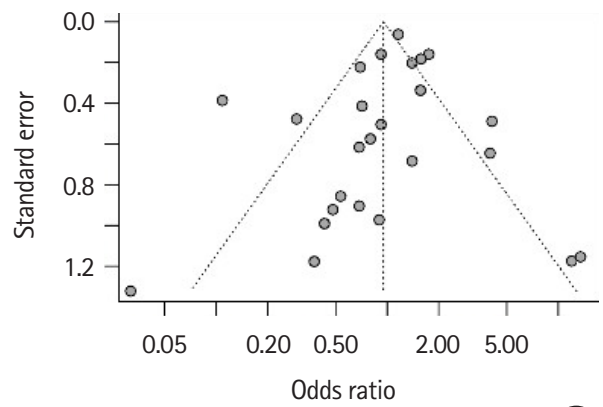

B

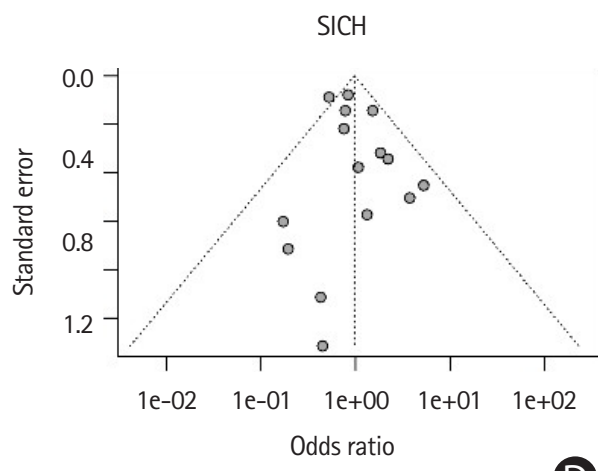

(D)

Supplementary Figure 2. Funnel plots of meta-analysis per outcomevariable. (A) Modified Treatment in Cerebral Infarction (mTICl) 2b-3, (B) modified Rankin Scale (mRS) 0-2 at 3 months, (C) death by 3 months, and (D) symptomatic intracranial hemorrhage (SICH). 